\title{
Reformas curriculares e o ataque ao pensamento reflexivo: o sutil desaparecimento da filosofia no currículo da Educação Básica no Brasil
}

\author{
Curricular reforms and attack on reflective thinking: the subtle disappearance of \\ philosophy in curriculum of the Basic Education in Brazil
}

\begin{abstract}
Altair Alberto Fávero
Professor doutor na Universidade de Passo Fundo, Passo Fundo, Rio Grande do Sul, Brasil. altairfavero@gmail.com - https://orcid.org/0000-0002-9187-7283
\end{abstract}

\section{Junior Bufon Centenaro}

Doutorando na Universidade de Passo Fundo, Passo Fundo, Rio Grande do Sul, Brasil. junior.centenaro@bol.com.br - https://orcid.org/0000-0003-3046-3885

\section{Antonio Pereira dos Santos \\ Graduando na Universidade de Passo Fundo, Passo Fundo, Rio Grande do Sul, Brasil. antoniops1993@gmail.com - https://orcid.org/0000-0002-3530-6582}

Recebido em 24 de fevereiro de 2020

Aprovado em 08 de abril de 2020

Publicado em 30 de julho de 2020

RESUMO: O presente ensaio tem por objetivo analisar a exclusão/flexibilização da filosofia pelas reformas curriculares como uma das faces do ataque ao pensamento reflexivo. Busca-se problematizar a maneira como as reformas educacionais em curso representam um ataque ao pensamento reflexivo na medida que realizam um processo sutil de exclusão da filosofia no currículo da educação básica. O ensaio está estruturado em duas partes: na primeira parte, apresenta-se uma análise sobre a flexibilização/exclusão da filosofia e do pensamento reflexivo induzidos pela Lei 13.415/17 e pela BNCC (Base Nacional Comum Curricular); na segunda parte far-se-á uma defesa da permanência da filosofia nos currículos como prerrogativa para desenvolver o pensamento reflexivo, considerado imprescindível para o pleno desenvolvimento da pessoa humana e para as relações democráticas. Nas considerações finais, são apontados desafios políticos e pedagógicos enquanto compromissos para o campo do ensino de filosofia no Brasil. A metodologia que estrutura o presente ensaio está ancorada no método analítico-hermenêutico, com especial ênfase nos procedimentos de pesquisa bibliográfica e pesquisa documental em políticas curriculares. Palavras-chave: Pensamento reflexivo; Ensino de filosofia; BNCC; Reforma do ensino médio.

ABSTRACT: This essay aims to analyze the exclusion/flexibility of philosophy by curriculum reforms as one of the faces of the attack on reflective thinking. It seeks to problematize the way in which the educational reforms underway represent an attack on reflective thinking as they carry out a subtle process of excluding philosophy from the curriculum of the basic education. The essay is structured in two parts: in the first part we present 
an analysis on the flexibilization/exclusion of philosophy and reflective thinking induced by Law $13.415 / 17$ and by BNCC (Base Nacional Comum Curricular); in the second part there will be a defense of the permanence of philosophy in the curricula as a prerogative to develop reflective thinking, considered essential for the full development of the human person and for democratic relations. In the final considerations, political and pedagogical challenges are pointed out as commitments for the field of teaching philosophy in Brazil. . The methodology that structures the present essay is anchored in the analytical-hermeneutic method, with special emphasis on bibliographic research procedures and documentary research in curricular policies.

Keywords: Reflective thinking; Philosophy teaching; BNCC; High school reform.

\section{Introdução}

Em meados do século XX, o filósofo existencialista Karl Jaspers, que também foi orientador da tese doutoral de Hannah Arendt, manifestava de forma contundente o profundo desconforto que sofre a filosofia num mundo cada vez mais tecnificado e utilitarista. Suas palavras encontram eco até os dias de hoje: "um instinto vital ignorado de si mesmo, odeia a filosofia. Ela é perigosa. Se eu a compreendesse, teria de alterar minha vida. Adquiriria outro estado de espírito, veria as coisas a uma claridade insólita, teria de rever meus juízos" (JASPERS, 1965, p.139). Passado mais de meio século, continua-se vendo um ataque explícito ao pensamento reflexivo, corroborando Jarpers (1965, p.139), quando denunciava que "muitos políticos vêem facilitado seu nefasto trabalho pela ausência da filosofia", pois "massas e funcionários são mais fáceis de manipular quando não pensam, mas tão-somente usam uma inteligência de rebanho".

Historicamente a filosofia foi uma sobrevivente. Não faltaram regimes de governo, pseudopensadores, empresários, elites econômicas dominantes e burocratas de plantão que utilizaram de todas as prerrogativas e estratégias para banir a filosofia da vida cotidiana das pessoas e, principalmente, excluí-la dos ambientes escolares e acadêmicos. No Brasil, tal processo foi notável no cenário da ditadura civil-militar, instaurada em 1964, e na forma como foi sutilmente excluída na LDB 9394/96. Em 2003, pesquisadores das cinco regiões brasileiras realizaram uma pesquisa por solicitação da Organização das Nações Unidas para a Educação, a Ciência e a Cultura (Unesco), visando mapear as condições do ensino de filosofia no país em diversos níveis, com especial ênfase na educação média. O relatório parcial dos resultados foi publicado no texto "O ensino de filosofia no Brasil: um mapa das condições atuais" (FÁVERO et al., 2004, p. 257-284). O relatório está organizado em três partes: primeiramente, apresenta o panorama das disciplinas de filosofia nos espaços curriculares do ensino médio, a trajetória das discussões introduzidas pela LDB 9394/96, um mapa detalhado do funcionamento dos cursos de filosofia em cada região, a filosofia nos demais níveis de ensino (fundamental e superior) e um balanço da atual configuração do ensino de filosofia no ensino médio; na segunda parte, trata dos programas, métodos e materiais de apoio utilizados no ensino de filosofia no ensino médio; por fim, na terceira parte, passa revisa a formação dos professores de filosofia e o exercício profissional.

O debate sobre a presença da filosofia no âmbito escolar foi amplamente discutido nos diversos fóruns e simpósios regionais e nacionais durante boa parte da primeira década do século XX, resultando em uma intensa produção acadêmica. Fávero (2002), 
em seu texto "Filosofia na sala de aula: pela força da lei ou pela opção políticopedagógica da sociedade", apresentado originalmente no II Simpósio Sul Brasileiro sobre Ensino de Filosofia, questiona de forma contundente se a presença da filosofia na escola deveria dar-se por um dispositivo legal ou por outros caminhos. Houve diversas mobilizações da sociedade para que a filosofia retornasse aos bancos escolares. A intensa luta acabou resultando na aprovação da Lei 11.684, de 2 de junho de 2008, que alterou o art. 36 da LDB (9.394/1996), estabelecendo a inclusão da Filosofia e da Sociologia "como disciplinas obrigatórias nos currículos do ensino médio" (BRASIL, 2008).

Carneiro (2019, p. 224) também remete à história do ensino de filosofia no Brasil, principalmente no período em que foi recebida "pela porta da frente" na escola: "não posso deixar de lado experiências bem-sucedidas que inspiram os jovens na experiência do pensamento". Nos últimos dez anos, foram construídas experiências importantes que explicitaram o papel da filosofia em despertar para o pensamento crítico, para a curiosidade e criatividade. Dessa forma, percebe-se que a filosofia percorreu uma história significativa, porém é insuficiente saber da sua importância; é preciso reconhecimento da sua obrigatoriedade e ações que acompanhem o aspecto legal da disciplina. Para Carneiro (2019), faz-se oportuno dizer que o retorno da filosofia como disciplina obrigatória exigiu da comunidade filosófica inúmeras ações formativas para consolidar sua intervenção escolar. Foram várias as iniciativas de articulação, como é o caso do fortalecimento dos programas de licenciatura em Filosofia. O autor pondera que a Lei 13.415/17, conhecida como Reforma do Ensino Médio, coloca em risco o campo do ensino de filosofia, pois "ela regride para um antigo argumento de que o conteúdo filosófico não prescinde de um lugar específico entre os componentes curriculares" (CARNEIRO, 2019, p. 225).

A histórica e intensa luta em prol do retorno da filosofia parecia ter sido vencida e esperava-se que, a partir de então, a filosofia poderia ter um espaço formal nos currículos do ensino médio. No entanto, em menos de 10 anos, a filosofia teve a obrigatoriedade formalmente retirada dos currículos escolares pela polêmica Lei 13.415/17. A Base Nacional Comum Curricular (BNCC) aprovada em 2018 consolidou essa supressão ao não estipular a filosofia como componente curricular, mas apenas como abordagem transversal na área de ciências humanas.

A partir da constatação desses elementos, objetiva-se, no presente ensaio, analisar a exclusão/flexibilização da filosofia pelas reformas curriculares como uma das faces do ataque ao pensamento reflexivo. Com isso, almeja-se problematizar a Reforma do Ensino Médio e a BNCC, indicando que ambas representam um retrocesso ao pensamento reflexivo. Este ensaio está estruturado em duas partes: na primeira parte, apresenta-se uma análise sobre a flexibilização/exclusão da filosofia e do pensamento crítico induzidos pela Lei 13.415/17 e pela BNCC; na segunda parte, defende-se a permanência da filosofia como prerrogativa para manter ativo o pensamento crítico, considerado imprescindível para o fortalecimento das sociedades democráticas. Por fim, nas considerações finais, apresentam-se possíveis horizontes para manter viva a presença da filosofia na escola e para além dela. Nussbaum (2015), Cara (2019), Frigotto e Motta (2017), Silva (2018), Laval 
(2004), Lipman (1990; 2008), Fávero (2002; 2015), Fávero e Centenaro (2016) e Aspis e Galo (2009) são alguns dos interlocutores presentes na construção do percurso deste ensaio.

\section{A flexibilização/exclusão da filosofia na BNCC e Lei 13.415/17}

As políticas curriculares, a partir de 2016, apresentaram um cenário desfavorável ao ensino de filosofia na educação básica brasileira. Em meados de 2016, a Medida Provisória 746, convertida mais tarde em Lei Federal 13.415/17 instalou uma conjuntura de flexibilização/ exclusão da filosofia como componente curricular. A referida Lei revogou o inciso IV do Art. 36 da LDB 9394/96, que determinava: "serão incluídas a Filosofia e a Sociologia como disciplinas obrigatórias em todas as séries do ensino médio" (BRASIL, 2008); e, em substituição, acrescentou ao $\S 2^{\circ}$ do Art. 35: "A Base Nacional Comum Curricular referente ao ensino médio incluirá obrigatoriamente estudos e práticas de educação física, arte, sociologia e filosofia" (BRASIL, 2018). Dessa forma, o futuro da filosofia no currículo do ensino médio dependeria da proposta da BNCC para esta etapa. Em dezembro de 2018, por meio da Resolução $n^{\circ}$ 4, o Conselho Nacional de Educação aprovou a BNCC do Ensino Médio e o que já era esperado se confirma - a filosofia volta a ser incluída no currículo como transversal ${ }^{1}$ na área denominada de ciências humanas e sociais aplicadas. Conforme o documento, "A BNCC na área de Ciências Humanas e Sociais Aplicadas [é] integrada por Filosofia, Geografia, História e Sociologia" (BRASIL, 2018, p. 561). Contudo, ao observar a Base, na área de humanas e sociais aplicadas, percebe-se que são suprimidos os componentes curriculares e, em seu lugar, apresentadas seis competências específicas e suas respectivas habilidades para dar conta da área como um todo.

Essa configuração está ancorada na Lei $13.415 / 17$, que determinou, no Art. 35 , $\S$ $3^{\circ}$, que "O ensino da língua portuguesa e da matemática será obrigatório nos três anos do ensino médio, assegurada às comunidades indígenas, também, a utilização das respectivas línguas maternas" (BRASIL, 2017). Os mencionados componentes curriculares são obrigatórios nos três anos, enquanto que os demais não serão obrigatórios e podem ser oferecidos conforme a organização de cada sistema de ensino ou nos itinerários formativos, que serão escolhidos pelos estudantes. Como é possível observar, não há explicitamente nenhuma proibição com relação ao ensino de filosofia, porém, a não obrigatoriedade, em uma conjuntura educativa ainda fortemente pautada no ensino disciplinar, abre vários precedentes para a flexibilização/exclusão da filosofia no ensino médio, a qual os indicativos postulados anteriormente indicam um rápido percurso.

O termo flexibilização é adotado pelos formuladores das políticas curriculares, segundo os quais, a filosofia em nada será prejudicada². Porém, compreende-se que haverá uma gradual exclusão não só da filosofia, mas dos demais componentes curriculares de humanas, sobretudo no ensino médio. A não obrigatoriedade da filosofia permite aos sistemas de ensino - públicos e privados - organizar a oferta da disciplina conforme considerarem necessário, havendo aí precedente para oferta mínima ou não oferta, já que a lei obriga apenas o ensino de práticas e estudos. Além disso, os sistemas de ensino 
podem estruturar itinerários formativos de ciências humanas e sociais aplicadas, entretanto, eles são optativos, ou seja, o aluno pode escolher não cursar um itinerário de humanas, por exemplo. Se confirmadas e implementadas as reformas, uma diversificada gama de conteúdos, práticas e abordagens ligadas à filosofia deixarão de compor a formação básica dos estudantes brasileiros, o que representa um profundo retrocesso diante dos próprios parâmetros constitucionais do Art. 205, os quais estabelecem que a educação visa ao "pleno desenvolvimento da pessoa, seu preparo para o exercício da cidadania e sua qualificação para o trabalho" (BRASIL, 1988), bem como para o desenvolvimento do pensamento reflexivo.

É importante ressaltar que o problema do desaparecimento silencioso das humanidades nos currículos da educação básica não é exclusividade do caso brasileiro, mas integra um conjunto de políticas influenciadas por organismos multilaterais. Nesse sentido, as pesquisas de Schneider e Nardi (2019) demonstram que, já na década de 1990, diversos organismos multilaterais atuavam em favor de reformas nos sistemas educacionais dos países latino-americanos. O exemplo investigado pelos autores trata-se do Programa de Promoção da Reforma Educativa na América Latina e Caribe (Preal), financiado por um consórcio entre BID/Banco Mundial/Diálogo Interamericano. O objetivo declarado desse programa era "promover a melhoria da qualidade do ensino em países latino-americanos e caribenhos, pela introdução e monitoramento de políticas públicas na área da educação" (SCHNEIDER; NARDI, 2019, p. 79). O percurso das políticas para a educação básica, formuladas a partir da tônica do Preal, relegou considerável primazia ao estabelecimento "de standards educacionais gerais, de conteúdo e desempenho, que determinam o que se espera que os estudantes alcancem em cada etapa escolar" e de "um conjunto de informações confiáveis em relação aos resultados dos alunos, ao desempenho das escolas e às medidas que devem ser tomadas para melhorá-las" (SCHNEIDER; NARDI, 2019, p. 84).

A própria BNCC, em sua introdução, ao explicitar os fundamentos pedagógicos que a embasam, apresenta sua filiação a esse conjunto de parâmetros difundidos pelos organismos. Ao demarcar o foco no desenvolvimento de competências como fio condutor de toda a proposta, a Base torna claro que:

É esse também o enfoque adotado nas avaliações internacionais da Organização para a Cooperação e Desenvolvimento Econômico (OCDE), que o Programa Internacional de Avaliação de Alunos (Pisa, na sigla em inglês), e da Organização das Nações Unidas para a Educação, a Ciência e a Cultura (Unesco, na sigla em inglês), que institui o Laboratório Latino-americano de Avaliação da Qualidade da Educação para a América Latina (LLECE, na sigla em espanhol); (BRASIL, 2018, p. 13).

As políticas curriculares nas últimas duas décadas passaram a almejar um currículo nacional padronizado e enfatizar avaliações padronizadas (Pisa, Enem, Prova Brasil) e a produzir rankings de acordo com os resultados dessas avaliações, com o objetivo de melhorar os resultados e os índices educacionais. Essas avaliações medem a qualidade da educação pela proficiência em leitura, escrita, matemática e ciências. Para isto, 
segundo Motta e Frigotto (2017, p. 365), flexibiliza-se o currículo para facilitar a escolha de disciplinas mais úteis às avaliações de larga escala e busca-se "desenvolver habilidades e competências que facilitem o ingresso no mercado de trabalho, formal ou informal, ou que proporcionem ocupações que venham a gerar renda". A educação reduzida a um insumo econômico se reflete no Programme for international Student Assessment (Pisa), uma iniciativa da OCDE, "organização internacional pautada na economia de mercado, que fornece uma plataforma para comparar e padronizar programas econômicos, propor soluções liberalizantes e coordenar políticas domésticas e internacionais" (CARA, 2019 , p. 28). No Brasil, a criação do Índice de Desenvolvimento da Educação Básica (IDEB), em 2007, estabeleceu metas de desempenho dos estudantes pautadas no Pisa.

Salvos os avanços proporcionados por esses modelos, vale ressaltar que a educação não pode resumir-se a isso, ou seja, o debate sobre a qualidade da educação básica transcende as métricas proporcionadas pelas avaliações em larga escala. De acordo com Cara, as métricas das avaliações do modelo Pisa "não levam em conta as condições de trabalho dos educadores, que enfrentam baixas remunerações, carreiras pouco atrativas, salas de aula superlotadas e escolas infraestrutura indigna" (CARA, 2019, p. 28). Esses elementos e outros, como a situação social e econômica dos estudantes influenciam no processo de ensino-aprendizagem, porém, são desconsiderados, na medida em que os índices consideram apenas os resultados de aprendizagem/proficiência e muito pouco o processo educativo real.

Permanece latente a seguinte questão: qual a relação dessas políticas influenciadas por organismos multilaterais com a flexibilização/exclusão das humanidades dos currículos? De acordo com Silva (2018), a BNCC reassume um modelo educacional baseado na pedagogia das competências, que norteou as políticas curriculares brasileiras na década de 1990 e início dos anos 2000. "A definição de competências como eixo de prescrições curriculares foi favorecida, no contexto da reforma curricular da década de 1990, em virtude de sua proximidade com a ideia de competição e de competitividade" (SILVA, 2018, p. 11). Além disso, a proposta de currículo por competências é retomada "em meio às mesmas justificativas, de que é necessário adequar a escola a supostas e generalizáveis mudanças do 'mundo do trabalho', associadas de modo mecânico e imediato a inovações de caráter tecnológico e organizacional" (SILVA, 2018, p. 11). As disciplinas consideradas "demasiado teóricas" devem, segundo a ótica dos reformadores, ceder espaço às competências e habilidades práticas em vista de adequação imediata ao mundo trabalho.

A BNCC, ao fazer uma opção clara com relação ao currículo por competências (BRASIL, 2018), passa a estruturar toda a educação básica de acordo com o desenvolvimento de competências e habilidades. Tê-las por base, para a formação humana, viabiliza "uma escola pautada em critérios como eficiência e produtividade (SILVA, 2018, p. 12). Os organismos multilaterais, influenciadores de políticas educativas, conforme observam Schneider e Nardi (2019, p. 79), são proeminentes intelectuais orgânicos, que atuam "em favor de reformas que atendam necessidades empresariais e de seus parceiros". Essa questão é abordada também por Laval (2004) em sua instigante obra A escola não é uma empresa. Tal abordagem 
diz respeito ao envolvimento da escola no novo capitalismo, a introdução das lógicas de mercado no campo educativo e as novas formas e poder gerencial dentro da escola. Laval (2004, p.20) argumenta "que o sistema educativo está a serviço da competitividade econômica, está estruturado como um mercado, deve ser gerido ao modo das empresas". O autor analisa os efeitos da insurgência do neoliberalismo sobre a educação pública, argumentando que as transformações produzidas pelo neoliberalismo afetam "o lugar e a natureza dos conhecimentos" na educação. "O saber não é mais um bem a adquirir para participar de uma essência universal do ser humano, [...], mas um investimento mais ou menos rentável para os indivíduos igualmente dotados e talentosos" (LAVAL, 2004, p. 22).

Os novos critérios de eficiência e eficácia - oriundos do discurso empresarial - mudam por completo o sentido da escola, pois ela não é mais o local de assimilação e de presença frequente das grandes narrações que forjam caracteres estáveis para situações sociais bem definidas; "ela é lugar de formação de caracteres adaptáveis às variações existenciais e profissionais em movimento incessante" (LAVAL, 2004, p. 23).

Os tomadores de decisão, agentes formuladores de políticas educacionais, visam um esforço em matéria de escolarização, e, segundo Laval (2004, p. 24), "pleiteiam, de preferência, um 'aumento' desse esforço, com a condição, todavia, de que ele se concentre no saber-fazer e nos saberes úteis, supostamente melhor adaptados aos jovens vindos das classes populares e correspondendo às necessidades das empresas". Há, então, uma dupla e paradoxal reivindicação: de um lado, o discurso em favor dos investimentos em educação; e, de outro, a favor da redução de conhecimentos considerados inúteis e enfadonhos por não terem ligação evidente com a prática e com os interesses econômicos (LAVAL, 2004). A análise de Laval indica que a teoria do capital humano passa a colonizar a educação a partir da atuação dos organismos multilaterais na definição das políticas públicas desta área.

Por capital humano, os economistas designam o "estoque de conhecimentos valorizáveis economicamente e incorporados aos indivíduos" (OCDE, 2014, p.5). Para tanto, a necessidade de promover "qualificações" tanto por meio do "sistema de formação" quanto pela "experiência profissional". Os organismos internacionais são convergentes ao se referirem à ideia de capital humano como estratégia de desenvolvimento. Num documento de 2014, por exemplo, intitulado "Fomentando o desenvolvimento inclusivo na produtividade da América Latina", a OCDE, ao falar da "base do capital humano", ressalta: "é essencial que se promova o amplo acesso à educação de qualidade e ao treinamento profissionalizante, para aumentar a coesão social e fomentar o crescimento da produtividade agregada do trabalho" (OCDE, 2014, p. 5). Fica implícito que a ideia de capital humano reuniria "os conhecimentos, as qualificações e as competências individuais" e que "o desenvolvimento das habilidades de jovens e adultos, preparando-os para o aprendizado contínuo, portanto, deve ser uma prioridade" (OCDE, 2014, p. 5).

O sucesso da concepção de capital humano nos organismos internacionais se deu principalmente, como ressalta Laval (2003, p. 26), "porque ela dá uma justificativa econômica 
às despesas educativas, a única que tem valor hoje em dia aos olhos dos que têm poder de decisão". Assim, a ideia de capital humano foi se consolidando como uma forma de investimento para que a produtividade e a concentração de capital pudessem ser potencializadas. Laval (2003, p. 26-27) adverte: “essa metáfora do 'capital humano' desemboca, todavia, em uma visão muito empobrecida dos efeitos do 'investimento no saber', essencialmente considerado como uma fonte de ganhos de produtividade". De fato, o capital humano passou a ser visto como um bem privado, dentro de uma concepção estritamente individualista, em que "o indivíduo possui recursos próprios que ele vai tentar fazer crescer ao longo de sua existência para aumentar sua produtividade, sua renda e suas vantagens sociais". Se for um investimento do indivíduo, então se deve desresponsabilizar o Estado de promover uma educação pública de qualidade, ficando, nesse caso, sob a responsabilidade da empresa, da família ou outras organizações. Diversificar as fontes de financiamento, de acordo com Laval (2004, p. 28), "aparece como a única via racional, já que ela faz com que os casais se encarreguem de uma parte crescente das despesas, na proporção das vantagens pessoais que eles obtenham".

No caso brasileiro, a Lei 13.415/17 é um exemplo marcante de que se considera a educação pautada pelo investimento em capital humano o motor do desenvolvimento econômico e, além disso, uma concepção de formação humana atrelada às necessidades do mercado. Sobre esse aspecto, Motta e Frigotto (2017, p. 358) afirmam que a reforma do ensino médio "enfatiza os conhecimentos úteis que o estudante deve adquirir para impulsionar a produtividade dos setores econômicos, a fim de potencializar a competitividade nos mercados local e internacional, ou para criar condições de empregabilidade". Em outras palavras, "desenvolver habilidades e competências que potencializem a inserção do indivíduo no mercado de trabalho" (MOTTA; FRIGOTTO, 2017, p. 358). A BNCC, ao adotar o enfoque das competências, "indica que as decisões pedagógicas devem estar orientadas", sobretudo, "por meio da indicação clara do que os alunos devem 'saber fazer', considerando a mobilização de conhecimentos, habilidades e atitudes para o exercício da cidadania e do mundo do trabalho" (BRASIL, 2018, p. 13).

Motta e Frigotto (2017) demonstram que esse discurso é marcadamente falacioso e ideológico por encobrir a realidade do ensino médio brasileiro e as condições reais do mercado de trabalho. A suposta necessidade de transformar o ensino médio em etapa qualificadora de mão de obra para as empresas que estariam necessitadas de mão de obra qualificada esbarra na dura realidade do mercado de trabalho.

Justificar que os setores econômicos não se expandem por se 'ressentirem da falta' de profissionais qualificados não corresponde com a realidade, pois nos curtos momentos de expansão do capital brasileiro a força de trabalho demandada foi para o trabalho simples. (MOTTA; FRIGOTTO, 2017, p. 359).

Desse modo, a tese desses autores aponta como verdadeira intenção da reforma do ensino médio a promoção de uma educação que: realize uma administração da questão social; adapte os estudantes às supostas e generalizáveis necessidades do 
mercado de trabalho; não gere revoltas populares, com a mistificação de que o sistema econômico neoliberal fornece igualdade de oportunidades para todos. Sendo assim, pode-se afirmar que há um conjunto de elementos que indicam o ataque ao pensamento reflexivo na escola, que, como será demonstrado mais adiante, é justamente um elemento central para enfrentar uma concepção instrumental e administrada de educação.

Diagnóstico semelhante integra as reflexões de Nussbaum (2015), que apresenta um instigante manifesto sobre o papel das humanidades na educação em vista do futuro da democracia. Para Nussbaum (2015, p. 4), "Tanto no ensino fundamental e médio, como no ensino superior, as humanidades e as artes estão sendo eliminadas em quase todos os países do mundo". E, além disso, estão sendo consideradas pelos governantes como enfeites inúteis, dado que "as nações precisam eliminar todos os elementos inúteis para se manterem competitivas no mercado global" (NUSSBAUM, 2015, p.4). As humanidades e as artes, a partir de estudos realizados por Nussbaum (2015, p.4) nos sistemas educativos de vários países - entre eles Estados Unidos e Índia - estão perdendo lugar nos currículos, e algo ainda pior, "nas mentes e corações dos pais e dos filhos" (NUSSBAUM, 2015, p. 4). A análise de Nussbaum (2015) é fundamental para compreender as políticas curriculares em curso no Brasil, em que há uma visível redução do espaço das humanidades no currículo, sobretudo da filosofia, representando, assim, uma das faces do ataque ao pensamento reflexivo na escola. Sobre essa questão,

O que poderíamos chamar de aspectos humanistas da ciência e das
ciências humanas - o aspecto construtivo e criativo, e a perspectiva
de um raciocínio crítico rigoroso - também está perdendo terreno, já
que os países preferem correr atrás do lucro de curto prazo por meio
do aperfeiçoamento das competências lucrativas e extremamente
práticas adequadas à geração de lucro. (NUSSBAUM, 2015, p. 4).

Argumentou-se até aqui, com base em autores do campo das políticas educacionais ou que realizam um diálogo com elas, e também nos documentos de política curricular, elementos que revelam a flexibilização/exclusão da filosofia e das humanidades dos currículos da educação básica. Os estudos dessas fontes assinalam que esse processo está ancorado em perspectivas neoliberais, de uma educação cada vez mais reduzida à produção de capital humano e de competências e habilidades instrumentais, sobretudo pela filiação das políticas curriculares analisadas à ideologia empresarial e aos parâmetros dos organismos multilaterais.

\section{Em defesa da permanência da filosofia e do pensamento reflexivo na educação básica}

Defender a permanência da filosofia no currículo da educação básica significa enfrentar barreiras impostas ao pensamento reflexivo por meio das reformas curriculares de inspiração neoliberal. Essa atitude pedagógica e política exige que se observe, ao menos em linhas gerais, uma concepção de pensamento reflexivo associada ao ensino 
de filosofia. Sobre esse aspecto, encontra-se, na obra de Matthew Lipman (1923-2010), uma vasta produção teórica e metodológica sobre o ensino de filosofia na escola, elaborada depois de décadas de desenvolvimento de uma proposta de ensino pautada pela experiência filosófica de pensamento. Lipman e seus colaboradores puderam analisar nas escolas que acolheram a proposta, com dados e informações qualificadas, que a filosofia, desde os primórdios da educação básica, é fundamental, por introduzir diferenças significativas no desempenho global dos alunos, qualificando a leitura, o raciocínio e a criatividade (LIPMAN; OSCANYAN; SHARP, 2014). De modo geral, a filosofia desenvolve as habilidades de raciocínio autônomo e, consequentemente, tem relevância para a sociabilidade humana, para a convivência democrática. É nesse viés que Lipman (1990, p. 33) afirma: "se lamentamos nossos líderes e nossos eleitores por serem egoístas e não esclarecidos, devemos lembrar que eles são produtos de nosso sistema educacional". Nessa afirmação está implícito que, de algum modo, a escola é responsável pela qualidade do pensamento racional presente na sociedade, ou, ainda, que a escola não pode ignorar seu papel no desenvolvimento do raciocínio das crianças e dos adolescentes.

Para Lipman (2008, p. 41), o pensar reflexivo ou pensamento de ordem superior "representa a fusão dos pensamentos crítico e criativo". Isso significa que um pensamento de excelência conta ao mesmo tempo com racionalidade e criatividade. Um terceiro componente integra o pensar reflexivo, o pensamento complexo, que consiste na relação entre os procedimentos metodológicos e a parte substantiva (conteúdo) do pensar. O pensar crítico é orientado por critérios, é autocorretivo e sensível ao contexto, envolve raciocínio e julgamento crítico. O pensar criativo é sensível aos critérios, autotranscendente e governado pelo contexto, envolve habilidade, talento e julgamento criativo (LIPMAN, 2008). Essa definição é marcante em dois sentidos. Primeiro, porque reconhece a educação básica como lugar do domínio por parte do aluno das ferramentas do pensar em oposição às concepções de educação que privilegiam a assimilação de conteúdos estáticos e o desenvolvimento de habilidades práticas e instrumentais. O segundo, porque abre espaço para demonstrar a contribuição da filosofia para tal tarefa, dado que a experiência do pensamento filosófico por meio da investigação racional é essencial para a formação humana do sujeito.

Nesse sentido, compreende-se que o papel da filosofia é emergente e atual. Ao postular isso, é necessário evitar uma postura arrogante, que atribui somente à filosofia o papel de auxiliar o desenvolvimento do pensar reflexivo, e reconhecer que os demais componentes curriculares também atuam para tal objetivo. No presente ensaio, procura-se sustentar que há motivos suficientes para defender a permanência da filosofia como uma grande aliada dos demais componentes curriculares, na imperiosa tarefa de educar para o pensar. Sobre esse ponto, Lipman (2008, p.209) sugere: "qualquer disciplina que complemente o ensino do pensar sobre aquela disciplina com o ensino de pensar sobre (ou metodologia) o pensamento naquela disciplina entra na estimulação do tipo de pensar que chamei de complexo". Dessa forma, o pensar sobre o modo como o pensamento está sendo realizado nas disciplinas significa fortalecer as oportunidades de processos de investigação cuidadosos, atentos ao erro, com critérios claros de confiabilidade e de verdade, mesmo que provisória. $\mathrm{O}$ autor 
reforça esse argumento, sugerindo:

Mas é importante que uma disciplina seja aberta com seus alunos em relação a sua própria metodologia - suas suposições, suas definições, suas compreensões idiossincráticas, sua autoimagem, seus raciocínios e seus critérios - sou inclinado a crer que este é somente o início de um movimento na direção à filosofia. Precisamos de ambos: do pensar complexo em outras disciplinas e da filosofia no currículo. (LIPMAN, 2008, p. 210).

Vale ressaltar que o processo de abertura de cada disciplina para pensar sobre a própria metodologia precisa, sobretudo, integrar o exercício de pensamento de cada sujeito do processo educativo. Postular essa tarefa exige da escola e dos professores procedimentos e metodologias adequadas ao desenvolvimento do pensar reflexivo. Lipman (2008), atento a essa necessidade, desenvolveu, nos Estados Unidos, um Programa de Filosofia para Crianças no final dos anos de 1960, que, no final do século XX, se espalhou para mais de 40 países, dentre eles o Brasil. Não é objetivo deste ensaio explicar em detalhes o Programa, por isso se busca salientar alguns elementos centrais da proposta que permitem a defesa da permanência da filosofia e, consequentemente, do desenvolvimento do pensar reflexivo.

Sendo assim, na sequência destacam-se alguns aspectos nessa direção. Pode-se dizer que "uma civilização marcada pela mentalidade técnico-instrumental dificilmente consegue perceber a importância da filosofia no mundo de hoje" (FÁVERO, 2015, p.14). $E$, além disso, a filosofia passa por inúmeras interpretações equivocadas, pois "nossa sociedade e nossa cultura costumam considerar que alguma coisa só tem o direito de existir se tiver alguma finalidade prática, muito visível e de utilidade imediata" (FÁVERO, 2015, p. 14). Ao analisar a sociedade e o modelo de educação, Lipman (2008) assegura que a filosofia tem a ver com prazer, com o cultivo do espírito autocorretivo e, para a produção do saber, é preciso uma educação como investigação.

Com o objetivo de analisar a educação no viés da investigação, Lipman (2008) assegura que a filosofia é uma sobrevivente, em uma era em que a maioria das humanidades foi colocada contra a parede. A análise crítica de Lipman (2008) é um exame objetivo do quanto a filosofia tem responsabilidade em ser uma voz diferente dentre tantas outras. Partindo dessa objeção, percebe-se que essa disciplina precisa garantir o seu aspecto de autoformação, de crítica e de compromisso social. No que diz respeito às implicações práticas dessa disciplina, recupera-se Sócrates e sua compreensão de filosofia: não se tratava de uma aquisição nem de uma profissão, mas de um modo de vida.

Lipman (1990) pode ser considerado um herdeiro da pedagogia socrática e, ao escrever sobre filosofia com crianças, reflete a respeito de diversos aspectos da arte de educar e das habilidades para o pensar. Uma das palavras-chave e de suma importância dentro de seu aparato de escrita é investigação. Para o autor, "o objetivo não é dar às crianças teorias éticas acabadas pelas quais devam se conduzir, mas sim equipá-las com as ferramentas da reflexão dentro de um contexto de investigação" (LIPMAN, 1990, p. 67). É de suma importância, portanto, compreender o objetivo da educação 
básica, pois remete à tarefa primordial da filosofia, "a arte da autorreflexão". Mais do que conceitos prontos e acabados, a filosofia precisa criar nas crianças a capacidade de pensar criticamente e de fomentar habilidades racionais indispensáveis para a cidadania.

Nesse sentido, "a filosofia impõe que a classe se converta numa comunidade de investigação, onde estudantes e professores possam conversar como pessoas e como membros da mesma comunidade" (LIPMAN, 1990, p. 61). Do ponto de vista educacional, Lipman (1990) sugere transformar a sala de aula em "comunidade de investigação", pois o pensar reflexivo ocorre com maior profundidade quando realizado em comunidade. Essa participação entre todos é fundamental na procura de razões para cada ponto de vista. $O$ prazer está na construção, no ato de descobrir, de criticar e deixar-se transformar. Levar os alunos a constituírem entre si habilidades de raciocínio por meio da ação dialógica se constitui um exercício de solidariedade, cooperação e sensibilidade entre os sujeitos da comunidade - professor(a) e alunos(as). Assim, "a maioria das crianças, independente da formação que tenha, entra no sistema educacional atenta e ávida por aprender, curiosa e confiante, mas muitas delas acham o processo sem sentido na medida em que percorrem o sistema" (LIPMAN, 1990, p. 66). As causas das crianças se tornarem apáticas e sem esperança são muitas, dentre elas o sistema escolar, que despeja no mundo sujeitos que ignoram os mecanismos de participação democrática da sociedade. Para Lipman (1990, p.67),

Antes de tudo, o sistema educacional tem de dar razões para os
alunos terem esperança; este é certamente o primeiro passo para
qualquer população que se sente desesperançada com a situação.
Por conseguinte, a criança deve ter a possibilidade de experimentar o
que é viver num contexto de respeito mútuo, de diálogo disciplinado,
de investigação cooperativa, livre de arbitrariedade e manipulação.

A comunidade investigativa, antes de tudo, é um espaço de diálogo, respeito e compromisso. Dar razões de esperança faz parte de um sistema educacional libertador, que tem em vista as transformações sociais e a dignidade da vida humana. Ao contrário da doutrinação, o ambiente investigativo enfatiza os valores primordiais para a vida e a constituição do ser. Dessa forma, formar bons cidadãos não diz respeito apenas a uma habilidade de pensamento, afinal "a sensibilidade para as sutilezas dos assuntos sociais requer todas as habilidades de pensamento que a filosofia possa cultivar" (LIPMAN, 1990, p. 67). É preciso desenvolver conceitos, forjar definições, fazer conexões, pois tais habilidades são primordiais para a cidadania. Todo esse processo de racionalidade visa à construção de valores em um contexto cooperativo e comunitário, longe da competição e do individualismo.

Nota-se que a proposta de Lipman (1990) evidencia problemas atuais na escola brasileira, as dificuldades de inserção dos alunos e a dificuldade do modelo educacional que visa apenas habilidades e competências. Mais do que evidências, as propostas que têm em vista as habilidades necessárias para o pensar, a educação de valores e a responsabilidade da filosofia para o fortalecimento do caráter impelem para a defesa da permanência da filosofia nas escolas. 
Uma vez que as crianças passam muito tempo de suas vidas na escola, é evidente que ela tem uma considerável responsabilidade por sua socialização. "Socialização", aqui, significa a aquisição de comportamento característico da boa cidadania. Uma das características mais marcantes de um bom cidadão é a prontidão em considerar o bem da sociedade juntamente com o seu próprio bem pessoal. (LIPMAN, 1990, p. 75).

Essa socialização passa pela prontidão em integrar os objetivos pessoais com os objetivos da sociedade. Tal característica diz respeito às responsabilidades da cidadania que são trabalhadas no ambiente escolar. O papel da filosofia no fortalecimento do caráter é indispensável, porque põe o aluno diante de experiências significativas para o contraponto com outras ideias, para o enfretamento de oposições e para a criação de argumentos baseados na racionalidade. Importante ressaltar que os ideais que guiam uma sociedade democrática precisam ser apresentados de forma problemática e sempre suscetíveis à investigação. "Tais ideias precisam ser apresentadas não como conceitos acabados, mas sim como conceitos que estão abertos e são contestáveis, convidando à discussão e à clarificação" (LIPMAN, 1990, p. 78). É, nesse sentido, que a filosofia precisa ser discutida como um saber indispensável em sala de aula, cujo valor está em formar ambientes de investigação, racionalidade e compromisso social.

Defender a filosofia do ponto de vista da comunidade de investigação é ter presente que o saber não é pronto e acabado, mas se faz através do diálogo consciente, do debate e de um processo responsável e crítico. Esse modo de vida conceituado na proposta educacional filosófica se adquire com exercícios, reflexão, por meio da dimensão construtiva e crítica. No dizer de Fávero (2015, p. 16), "a filosofia como questão ou processo contribui no desenvolvimento da capacidade de questionar, de rejeitar como dado inequívoco e evidencia imediata, que convence o senso comum e fundamenta parte dos pensamentos". O importante é a dimensão formativa da filosofia que se alcança pelo ato de questionar, de conceber perguntas e abrir-se a caminhos novos por meio do processo educacional.

Defender a filosofia é, antes de tudo, posicionar-se em defesa da formação de sujeitos capazes de agir racionalmente. O processo filosófico oferece às crianças e aos jovens a oportunidade de um aprendizado fecundo, a capacidade de discussão de conceitos e uma abordagem interdisciplinar. É importante notar que a filosofia não precisa ir muito longe para mostrar sua relevância com o bom pensar. O fazer filosofia "exige um pensar autocorretivo, é um pensar investigando a si mesmo com o propósito de se tornar um pensar melhor" (LIPMAN, 1990, p. 60). Compreende-se que a filosofia não está interessada apenas em si mesma, mas se volta para as outras áreas, questionando o pensar que acontece nelas. O processo de aprendizagem exige liberdade dos sujeitos e, dessa forma, a filosofia alcança o seu objetivo, ao transformar as salas de aulas em comunidade de investigação. Sobretudo, em possibilitar às crianças conceitos abertos e suscetíveis à clarificação. As respostas dadas pelos adultos, muitas vezes, não são interessantes, mas quando as crianças ajudam-se e se abrem ao 
aprendizado a sensação de liberdade acontece e o prazer em aprender torna-se presente.

Um dos desafios para a filosofia, defendidos por Fávero (2015, p. 23), "é assumir sua função emancipatória. Se o homem encontra na filosofia algum prazer, tem sido porque o cultivo desse tipo de saber lhe permite não só a possibilidade de domínio" de discussão e de conhecimento de si mesmo, "as principalmente, porque por meio da filosofia ele passou a tomar maior consciência de sua possível emancipação". Esse desafio implica distinguir, ao longo do percurso, qual o diálogo que leva à alienação e que atitudes levam à emancipação do sujeito.

Defender a filosofia é procurar garantir sua missão dentro das escolas, a partir de um processo pedagógico, capaz de levar em consideração a pertinência de sua reflexão. $O$ trabalho pedagógico que visa desenvolver o pensamento reflexivo demanda tempo, paciência, um percurso gradual e que respeite a individualidade de cada criança. As metodologias que exigem maior interação entre alunos e professores, diálogos e processos investigativos, assim como reflexão sobre a ação, são mais complexos do que o aprendizado de conteúdos e informações, ou das habilidades básicas em língua e matemática, que, por sua vez, são os requisitos das avaliações em larga escala. Ao passo que se poderia estar discutindo e planejando em escala nacional a qualificação da presença da filosofia na escola e seu papel no desenvolvimento do pensamento reflexivo, volta-se, infelizmente, à pauta do início do século $X X$, de lutar pela sua permanência nos currículos.

\section{Considerações finais}

Por fim, postulam-se duas ordens de desafios para uma defesa da filosofia e do pensamento reflexivo na educação básica. O primeiro conjunto de desafios reside na necessidade de continuar aperfeiçoando em termos pedagógicos a presença da filosofia nos currículos da escola. No ensaio "O pensar de ordem superior e o papel do diálogo investigativo no fazer filosofia na educação básica", Fávero e Centenaro (2016, p. 26), ao reconstruírem a ideia lipmaniana do pensar de ordem superior por meio do diálogo, ressaltaram que "a formação continuada docente" se constitui numa "tarefa intransferível para a possibilidade de êxito na promoção da educação para o pensar". Para tanto, destacam a necessidade de "converter" a sala de aula tradicional numa comunidade de investigação em que os alunos dividem opiniões respeitosamente, desenvolvem questões a partir das ideias dos outros, desafiando-se entre si para fornecer razões e opiniões até então não apoiadas, auxiliarem-se ao fazer inferências daquilo que foi afirmado. Sobre esse aspecto, Fávero e Centenaro (2016) destacam a expressão converter a sala de aula, que significa mudança radical do modo de pensar e de agir dos sujeitos envolvidos. Colocar-se na condição de questionador e investigador num processo dialógico de ensino e aprendizagem implica estar aberto ao diferente e conceber-se como um ser inacabado e em constante busca de conhecimento.

$\mathrm{Na}$ linha argumentativa em que se desenvolve o presente ensaio, reforçam-se as ponderações de Fávero e Centeraro (2016, p. 42-43), quando indicam que a presença da filosofia na escola e do pensamento reflexivo nas práticas escolares cotidianas significa dar espaço para "o aperfeiçoamento da criticidade", "o fortalecimento de propostas 
interdisciplinares" e "o fortalecimento de processos democráticos nas escolas". Na mesma direção, Lorieri e Rios (2004, p. 24) ressaltam que o pensamento filosófico é "uma forma de pensar reflexiva, crítica, profunda, metódica e abrangente que busca contextualizar, ou colocar em totalidades referências significativas mais amplas, aspectos importantes ou fundamentais da realidade e da existência humana". O pensamento filosófico ajuda a construir sentido, na dupla acepção do termo, pois indica direção e contribui para atribuir significado.

Sendo a filosofia uma manifestação histórica que testemunha de forma consistente as significações da realidade, acredita-se que um processo educativo de qualidade será incompleto se crianças e jovens estiverem destituídos do contato com o pensamento filosófico construído ao longo de mais de vinte e cinco séculos e que possibilita um olhar mais profundo da realidade na qual se encontram. Não se trata de reproduzir a história da filosofia ou restringir-se ao estudo dos diversos filósofos, mas possibilitar às crianças e aos jovens que desenvolvam desde cedo o espírito investigativo, inquietante, persistente, constante e criativo das significações. Trata-se de aprimorar a capacidade de fazer perguntas sobre as questões fundamentais da realidade, dos avanços dos conhecimentos, da ética, da tecnologia e da existência humana. Reforça-se, nesse sentido, o posicionamento de Aspis e Gallo (2009, p. 11) quando defendem que "o ensino de filosofia pode proporcionar aos jovens e crianças uma outra disciplina do pensamento" na medida que possibilita "pontar para uma outra chave de análise e de síntese para a construção de significado do mundo e de si próprio, além daqueles que já estão oferecidos normalmente em nossa educação".

O segundo conjunto de desafios, não menos importante que o primeiro, é a articulação política de instituições, órgãos, universidades e profissionais da área para garantir na estruturação das novas propostas curriculares locais a inclusão ou permanência da filosofia na educação básica. O intenso trabalho político e social que resultou na aprovação da Lei 11.684/2008 precisa, de algum modo, ser recuperado e reconfigurado diante dos dilemas atuais que envolvem a educação básica, por meio de reuniões com gestores dos sistemas de educação, fóruns e eventos, articulações políticas com associações representantes da pesquisa em educação em nível nacional. Essa tarefa poderá resultar em significativas conquistas, não só para o campo de ensino de filosofia, mas, sobretudo, para o desenvolvimento do pensar reflexivo e da formação de sujeitos críticos e democráticos.

O presente ensaio teve como objetivo analisar a exclusão/flexibilização da filosofia por meio das reformas curriculares como uma das faces do ataque ao pensamento reflexivo. Problematizou como a Lei $13.415 / 17$ e a BNCC excluem a filosofia como componente curricular, ignorando o percurso realizado nas últimas duas décadas de valorização, justificação e implementação da abordagem filosófica na educação básica. A principal causa dessa flexibilização/exclusão são as políticas de inspiração neoliberal, que possuem como eixo orientador a formação de habilidades básicas em linguagem e matemática e competências instrumentais para as demandas do mundo do trabalho. A filosofia, por ser um componente mais ligado à reflexão, ao pensamento abstrato e ao processo de formação humana, não é tida como essencial nesta conjuntura técnico-instrumental. Com amparo em literatura especializada na área, afirma-se que o desenvolvimento do 
pensamento reflexivo, crucial para a formação humana dos sujeitos e para a vitalidade da democracia, precisa da contribuição da filosofia como elemento de primeira ordem.

\section{Referências}

ASPIS, Renata Lima; GALLO, Sílvio. Ensinar Filosofia: um livro para professores. São Paulo: Atta Mídia e Educação, 2009.

BRASIL. Ministério da Educação. Base Nacional Comum Curricular. Brasília, DF: MEC, dezembro de 2018. Disponível em: http://download.basenacionalcomum.mec.gov.br/. Acesso em 19 de novembro de 2018.

BRASIL. Lei $\mathbf{n}^{\mathbf{1}} \mathbf{1 3 . 4 1 5 / 2 0 1 7}$. Altera as Leis 9.394/96 que estabelece as diretrizes e bases da educação nacional e 11.494/07 que regulamenta o FUNDEB e dá outras providências, 2017b. Disponível em: http://www2.camara.leg.br/legin/fed/lei/2017/lei-13415-16-fevereiro2017-784336-publicacaooriginal-152003-pl.html. Acesso em 20 de agosto de 2018.

BRASIL. Lei 11.684, de 2 de junho de 2008. Altera o art. 36 da Lei no 9.394/96 estabelece as diretrizes e bases da educação nacional, para incluir a Filosofia e a Sociologia como disciplinas obrigatórias nos currículos do ensino médio. Disponível em: http://www. planalto. gov.br/ccivil_03/_Ato2007-2010/2008/Lei/L11684.htm. Acesso em 13 de fevereiro de 2020.

BRASIL. Lei de Diretrizes e Bases da Educação Nacional $n^{\circ}$ 9.394/96. Presidência da República, Casa Civil, Subchefia para Assuntos Jurídicos, 1996.

CARA, Daniel. Contra a barbárie, o direito à educação. In: CÁSSIO, Fernando. (Org.) Educação contra a barbárie: por escolas democráticas e pela liberdade de ensinar. São Paulo: Boitempo, 2019.

CARNEIRO, S. R. G. Filosofia da base: o Ensino Filosófico em um currículo fragmentado. In: CASSIO, Fernando; CASTELLI JR., Roberto (orgs). Educação é a base? 23 educadores discutem a BNCC. São Paulo: Ação Educativa, 2019. p. 221-234.

FÁVERO, Altair Alberto; CENTENARO, Junior Bufon. O pensar de ordem superior e o papel do diálogo investigativo no fazer filosofia na educação básica. Revista Digital de Ensino de Filosofia, Santa Maria, vol. 2., n.2, p.26-57, jul./dez. 2016. Disponível em: https:// periodicos.ufsm.br/refilo/article/view/25101. Acesso em 10 jan.2019. doi: http://dx.doi. org/10.5902/2448065725101.

FÁVERO, Altair Alberto. Os desafios do ensino de filosofia: pensar-se a si mesmo. In: BRONDANI, Clóvis (org.). Ensino de filosofia: propostas e reflexões. Chapecó: UFFS, 2015.

FÁVERO, Altair Alberto et al. O ensino de filosofia no Brasil: um mapa das condições atuais. Cadernos Cedes, Campinas, vol.24, n.64, p.257-284, set./dez., 2004.

FÁVERO, Altair Alberto. Filosofia na sala de aula: pela força da lei ou pela opção políticopedagógica da sociedade. In: PIOVESAN, A. et al (orgs.). Filosofia e ensino em debate. ljuí: Unijuí, 2002, p.425-437.

FRIGOTTO, G; MOTTA, V. C. O por quê da urgência da reforma do ensino médio? Medida provisória $n^{\circ} 746 / 2016$ (lei n 13415/2017). Educação \& sociedade. Campinas, v. 38, $n^{\circ}$. 139, p. 355-372, abr-jun, 2017. Disponível em: http://www.scielo.br/scielo.php?pid=S010173302017000200355\&script=sci_abstract\&tlng=pt. Acesso em: 20 ago. 2018. doi: doi. org/10.1590/es0101-73302017176606. 
JASPERS, Karl. Introdução ao pensamento filosófico. São Paulo: Cultrix, 1965.

LAVAL, Christian. A escola não é uma empresa: o neo-liberalismo em ataque ao ensino público. Tradução de Maria Luiza M. de Carvalho e Silva. Londrina: Planta, 2004.

LIPMAN, Matthew. O pensar na educação. Tradução de Ann Mary Fighiera Perpétuo. Petrópolis: Vozes, 2008.

LIPMAN, Matthew. A filosofia vai à escola. Tradução de Ann Mary Fighiera Perpétuo. Petrópolis: Vozes,1990.

LIPMAN, Matthew.; SHARP, Ann Margaret; OSCANYAN, Frederick S. Filosofia na sala de aula. Tradução de Ana Luiza Fernandes Falcone. 2. ed. São Paulo: Nova Alexandria, 2014.

LORIERI, Marcos Antonio; RIOS, Terezinha Azeredo. Filosofia na escola: o prazer da reflexão. São Paulo: Moderna, 2004.

NUSSBAUM, Martha. Sem fins lucrativos: por que a democracia precisa das humanidades. Tradução de Fernando Santos. São Paulo: Martins Fontes, 2015.

SCNHEIDER, Marilda Paschoal; NARDI, Elton Luiz. Políticas de accountability em educação: perspectivas sobre avaliação, prestação de contas e responsabilização. ljuí: Ed. Unijuí, 2019. 129p.

SILVA, Monica Ribeiro da. A BNCC da reforma do ensino médio: o resgate de um empoeirado discurso. Educação em Revista, Belo Horizonte, 34, 22 Outubro 2018. 1-15. Disponivel em: http://www.scielo.br/scielo.php?script=sci_abstract\&pid=S010246982018000100301\&lng=pt\&nrm=iso_. Acesso em: 21 Dezembro 2018. doi: https://doi. org/10.1590/0102-4698214130.

\section{Notas}

${ }^{1}$ Essa compreensão de filosofia como "temas transversais" marcou as diretrizes educacionais nos dois mandatos de Fernando Henrique Cardoso (1995-2002) e no primeiro mandato de Luiz Inácio Lula da Silva (2003-2006).

${ }^{2}$ Conforme matéria publicada na Revista Época, de acordo com a ex-secretária executiva do MEC Maria Helena Guimarães de Castro, entre as novidades está "a flexibilização do ensino médio a partir da segunda metade do $2^{\circ}$ ano. [...]. Para se formar no ensino técnico, o estudante deverá cursar o currículo regular, aquele que é comum a todos, por um ano e meio. Essa etapa deverá abordar o que é essencial. A partir daí, ele poderá optar por um curso técnico, com um ano e meio ou dois anos de duração. Ou seja, em cerca de três anos, terá dois diplomas". O novo ensino médio, segundo essa concepção, passa a ser predominantemente de formação técnico-profissional. https://epoca.globo.com/ideias/noticia/2016/08/maria-helena-guimaraesha-um-tedio-generalizado-entre-os-alunos-do-ensino-medio.html

\section{Correspondência}

Altair Alberto Fávero - Rua Alfredo Chaves, 34, Bairro Lucas Araújo, CEP: 99074-270, Passo Fundo, Rio Grande do Sul, Brasil.

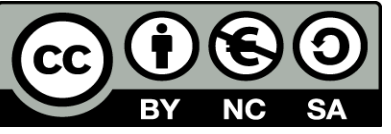

This work is licensed under a Creative Commons Attribution-NonCommercial 4.0 International (CC BY-NC 4.0) 